\title{
KARAKTERISTIK SIFAT KIMIA LAHAN GAMBUT YANG DI KONVERSI MENJADI PERKEBUNAN SAWIT DI KABUPATEN KETAPANG
}

\author{
Sarwendah Ratnawati Hermanto ${ }^{1}$, Venti Jatsiyah ${ }^{2}$ \\ Politeknik Negeri Ketapang, Jalan Rangga Sentap-Dalong, Ketapang Kalbar \\ Program Studi Budidaya Tanaman Perkebunan, Politeknik Negeri Ketapang, Kalbar \\ e-mail: sarwendah.ratnawati.hr@gmail.com
}

Diterima: 30 September 2018 / Disetujui: 27 November 2018 / Dipublikasi online: 15 Desember 2018 DOI: $10.22437 /$ chp.v3i2.5662

\begin{abstract}
Utilization of peatland as plantation land requires special attention and proper management because the development of plantations is highly dependent on soil fertility status. Conversion of peatlands into plantations impacts on native peat ecosystems. The aim of this research is to study the changes in chemical properties of peatlands converted into oil palm plantations and study the effects of peatland conversion into oil palm plantations at various ages of planting on changes in soil chemical properties. The research conducted was observational research. The sampling location is at 4 points in the Sungai Melayu area, namely pure peatland, oil palm plantations aged 2 years, 8 years and 16 years. Based on the results of the research, it was obtained data that the content of some soil chemical properties underwent changes, such as $\mathrm{pH}, \mathrm{CEC}, \mathrm{C}$-organic, $\mathrm{N}$-total, P-available and base Cations $(K$, $\mathrm{Ca}, \mathrm{Mg}$ and $\mathrm{Na}$ ). The increase in the $\mathrm{pH}$ of peatland converted to oil palm plantations is 0.1 $0.4 \%$. As for the value of CEC, C-organic, $N$-total, P-available and base Cations decreased with varying prices. The functional shift of peatland into oil palm plantations is very influential on soil fertility. Fertilization treatment as an effort to restore nutrients transported by plants during harvest does not take place optimally. Thus, there is a need to improve soil nutrient so that conditions do not worsen.
\end{abstract}

Keywords: Functional shift, Peat lands, Oil Palm, Chemistry

\begin{abstract}
ABSTRAK
Pemanfaatan lahan gambut sebagai lahan perkebunan memerlukan perhatian khusus dan manajemen yang tepat karena pengembangan perkebunan sangat tergantung pada status kesuburan tanah. Konversi lahan gambut menjadi perkebunan berdampak pada ekosistem gambut asli. Penelitian ini bertujuan untuk mempelajari perubahan sifat kimia lahan gambut yang dikonversi menjadi perkebunan sawit dan mempelajari dampak dari alih fungsi lahan gambut menjadi perkebunan sawit pada berbagai usia tanam terhadap perubahan sifat kimia tanah. Penelitian yang dilakukan ialah penelitian observasi. Lokasi pengambilan sampel ada di 4 titik di daerah sungai melayu, yaitu lahan gambut murni, kebun kelapa sawit usia 2 tahun, 8 tahun dan 16 tahun. Berdasarkan hasil penelitian, diperoleh data bahwa kandungan beberapa sifat kimia tanah mengalami perubahan, baik itu nilai $p H, K T K$, $\mathrm{C}$-organik, $\mathrm{N}$-total, $\mathrm{P}$ - tersedia dan Kation basa ( $\mathrm{K}, \mathrm{Ca}, \mathrm{Mg}$ dan $\mathrm{Na})$. Peningkatan $\mathrm{pH}$ lahan gambut yang dikonversi menjadi perkebunan kelapa sawit sebesar 0,1-0,4\%. Sedangkan untuk nilai KTK, C-organik, $N$-total, $P$ - tersedia dan Kation basa mengalami penurunan dengan harga yang bervariasi. Alih fungsi lahan gambut menjadi perkebunan sawit sangat berpengaruh pada kesuburan tanah. Perlakuan pemupukan sebagai upaya pengembalian hara yang terangkut oleh tanaman saat panen tidak berlangsung dengan optimal. Dengan demikian, perlu adanya upaya perbaikan hara tanah agar kondisi tidak semakin buruk.
\end{abstract}

Kata Kunci: Alih fungsi, Lahan Gambut, Sawit, Kimia 


\section{PENDAHULUAN}

Lahan gambut merupakan lahan yang kaya akan bahan organik, namun proses pelapukan yang belum terjadi secara sempurna. Pada kondisi alami lahan gambut menjadi habitat bagi beberapa jenis flora dan fauna (Agus \& Subiksa, 2008). Total area lahan gambut di Indonesia sekitar 27 juta ha, penyebaran terbesar terdapat di Sumatra, Kalimantan dan Papua dan hanya sedikit di Jawa, Halmahera dan Sulawesi (Rieley et al, 1997). Di Indonesia sekitar 3,72 juta ha (18\% dari total lahan gambut) telah dibuka dan diolah (Silvius dan Giesen, 1996) dan sedikitnya sekitar 500.000 ha telah diubah menjadi lahan pertanian (Notohadiprawiro, 1996).

Konversi lahan gambut yang menjadi lahan perkebunan akan berdampak pada ekosistem gambut asli. Kerusakan ekosistem berpengaruh terhadap lingkungan, mulai dari polusi gas rumah kaca, banjir, kekeringan hingga hilangnya keanekaragaman hayati (Agus \& Subiksa, 2008). Dampak kerusakan lahan gambut ini berkontribusi sangat besar terhadap lingkungan berupa tingginya kehilangan karbon (C) tanah dan besarnya jumlah $\mathrm{C}$ yang dilepaskan ke atmosfer, terjadi kekeringan di musim kemarau atau banjir pada musim hujan karena hilangnya fungsi gambut sebagai reservoir air tawar (Page dan Rieley, 1998).

Penentuan tingkat kesuburan pada lahan gambut dapat dilakukan dengan melakukan analisis sifat kimia tanah. Analisis sifat kimia tanah tersebut meliputi analisis kandungan unsur utama seperti $\mathrm{N}$ dan $\mathrm{P}$, tingkat kemasaman $(\mathrm{pH})$, kapasitas tukar kation (KTK), kandungan bahan organik $(\mathrm{C} / \mathrm{N})$, kation basa $(\mathrm{K}, \mathrm{Ca}, \mathrm{Mg}, \mathrm{Na})$ dan kandungan asam organik (Jumin, 1998). Kelapa sawit merupakan salah satu komoditas yang menjadi primadona dunia. Dalam dua dekade tersebut bisnis sawit tumbuh diatas $10 \%$ per tahun, jauh meninggalkan komoditas perkebunan lainnya yang tumbuh dibawah $5 \%$.

Dengan luas Kabupaten Ketapang sekitar $\pm 31.240,74 \mathrm{~km}^{2}$, potensi sumber daya lahan yang ada sangat mendukung untuk dikembangkannya komoditi sejenis. Namun, berlawanan dengan potensi tersebut, kondisi fisiografis Kabupaten Ketapang sebagian besar berada pada lahan gambut, menjadi tantangan bagi pengembangan kelapa sawit secara optimum.

Penelitian ini dapat dijadikan data awal dalam penelitian lanjutan lainnya sehingga didapatkan informasi tentang perbedaan sifat kimia lahan gambut yang di konversi menjadi perkebunan sawit dan dapat dijadikan informasi dasar bagi pemerintah dalam mengambil kebijakan yang berhubungan dengan perkebunan sawit di Kabupaten Ketapang Kalimantan Barat.

\section{METODOLOGI PENELITIAN}

Penelitian yang dilakukan ialah penelitian observasi. Lokasi pengambilan sampel ada di 4 titik di daerah Sungai Melayu, Kabupaten Ketapang yaitu lahan gambut murni, kebun kelapa sawit usia 2 tahun, 8 tahun dan 16 tahun. Alat dan bahan yang digunakan dalam penelitian antara lain: meteran, parang, cangkul, timbangan, paralon, tali rafia, 
GPS, kamera, tanah komposit, kantung plastik transparan, kertas label, alat-alat tulis serta bahan kimia untuk menganalisis sifat kimia tanah di laboratorium.

Pengambilan sampel dilakukan secara acak, permukaan tanah yang akan diambil dibersihkan dari vegetasi yang tumbuh di atasnya. Pengambilan sampel dilakukan dengan cara memasukkan paralon sepanjang $20 \mathrm{~cm}$ ke dalam tanah sampai paralon tenggelam seutuhnya. Sampel tanah yang telah diambil kemudian dikompositkan dan ditimbang seberat $1000 \mathrm{~g} /$ sampel dan dimasukkan kedalam plastik yang telah diberi label sebelumnya, kemudian di bawa ke laboratorium untuk dianalisis.

Penelitian ini menggunakan metode observasi. Data yang di sajikan merupakan data hasil analisis sifat kimia tanah gambut yang dilakukan di laboratorium meliputi: $\mathrm{pH}, \mathrm{KTK}$, C-organik, N-total, P- tersedia dan Kation basa (K, Ca, $\mathrm{Mg}$ dan Na). Penentuan pH dilakukan dengan membandingkan harga $\mathrm{pH}$ tanah $\left(\mathrm{H}_{2} \mathrm{O}\right.$ dan $\left.\mathrm{KCl}\right)$, Kapasitas Tukar Kation (KTK) dan basa kation ditentukan dengan ekstraksi $\mathrm{NH}_{4} \mathrm{OAC} 1 \mathrm{~N}$ pada $\mathrm{pH} 7$, nilai Corganik tanah diukur menggunakan metode Walkley and Black, nilai N-total tanah diperoleh dengan menggunakan metode Kjeldhal sedangkan nilai P-tersedia dihitung dengan metode Bray I. Data pendukung berupa data yang diperoleh dari hasil pengamatan secara langsung pada lokasi penelitian seperti, vegetasi dominan, curah hujan serta sejarah pengolahan lahan dan pemupukan yang dilakukan pada lokasi pengambilan sampel.

\section{PEMBAHASAN}

\section{Gambaran Umum Lokasi Penelitian}

Tanah gambut murni dan lahan gambut sawit usia 2 tahun yang dijadikan sampel merupakan lahan gambut yang berada di sepanjang jalan raya Pelang - Tumbang Titi, tepatnya di desa Pelang Kecamatan Matan Hilir Selatan Kabupaten Ketapang. Lahan gambut ini memiliki vegetasi dominan berupa palas-palasan, akasia dan senduduk. Sedangkan vegetasi dominan di lahan sawit usia 2 tahun ini yaitu Cyrtococcum oxyphyllum dan senduduk, serta palas-palasan.

Pada lahan sawit usia 2 tahun, pengolahan tanah yang dilakukan diawali dengan pembukaan lahan tanpa pembajakan. Pengendalian gulma dilakukan dengan penebasan rumput-rumput di sekitar dengan mesin tebas, sedangkan pengendalian gulma dalam masa perawatan tanaman dilakukan dengan penyemprotan herbisida sintetik (kimiawi). Perawatan piringan dilakukan dengan cara pembumbunan pada areal tanaman (tajuk). Pemupukan dilakukan dengan menggunakan pupuk Urea dalam kurun waktu 6 bulan sekali dan pupuk NPK sekali dalam setahun.

Kebun kelapa sawit usia 8 tahun dan 16 tahun yang dijadikan sampel terletak di jalan raya Pelang - Tumbang Titi, Desa Simpang Empat Kecamatan Sungai Melayu Rayak Kabupaten Ketapang. Vegetasi dominan di lahan sawit usia 8 tahun ini terdiri dari pakis pakisan, Eleusine indica, dan ilalang. Sedangkan vegetasi dominan di lahan sawit usia 16 
tahun ini terdiri dari pakis - pakisan, sambung rambat (Mikania micrantha), senduduk dan ilalang.

Pada lahan sawit usia 8 tahun, pengolahan tanah yang dilakukan diawali dengan pembukaan lahan menggunakan alat berat. Rumput di sekitar lahan ditebas dengan menggunakan mesin pemotong rumput. Pengendalian gulma dilakukan dengan penyemprotan herbisida sintetik (kimiawi). Di sekeliling kebun dibuat parit dengan ukuran $2 \mathrm{~m} \times 2 \mathrm{~m} \times 2 \mathrm{~m}$. Pembumbunan dilakukan sekali pada saat swit dalam masa TBM (Tanaman Belum Menghasilkan). Pemupukan dilakukan dengan menggunakan pupuk Urea dalam waktu 6 bulan sekali selama masa TBM, penggunaan pupuk NPK 15 dalam waktu 3 bulan sekali selama masa TM (Tanaman Menghasilkan) dan pupuk NPK Mutiara diberikan sekali dalam setahun.

Pada lahan sawit usia 16 tahun, pengolahan tanah yang dilakukan sebelum lahan gambut dijadikan perkebunan kelapa sawit diawali dengan pembukaan lahan menggunakan alat berat. Rumput di sekitar lahan ditebas dengan menggunakan mesin pemotong rumput. Pengendalian gulma dilakukan dengan penyemprotan herbisida sintetik (kimiawi). Pada perkebunan ini tidak dilakukan pembumbunan piringan dan pembuatan parit. Pemupukan dilakukan dengan menggunakan pupuk Urea dalam waktu 6 bulan sekali selama masa TBM, penggunaan pupuk NPK 15 dan pupuk Urea dalam waktu 3 bulan sekali selama masa TM (Tanaman Menghasilkan) serta pupuk NPK Mutiara diberikan sekali dalam setahun.

\section{Analisis Kimia Tanah}

Analisis sifat kimia tanah yang dilakukan meliputi analisis kandungan unsur utama seperti $\mathrm{N}$ dan $\mathrm{P}$, tingkat kemasaman $(\mathrm{pH})$, kapasitas tukar kation (KTK), kandungan bahan organik $(\mathrm{C} / \mathrm{N})$, kation basa $(\mathrm{K}, \mathrm{Ca}, \mathrm{Mg}, \mathrm{Na})$. Konversi lahan gambut menjadi perkebunan kelapa sawit menyebabkan terjadinya peningkatan $\mathrm{pH}$ tanah. Peningkatan $\mathrm{pH}$ yang terjadi tergolong rendah dan tidak terlalu signifikan karena masih tergolong pada kategori sangat asam. Peningkatan $\mathrm{pH}$ lahan gambut yang dikonversi menjadi perkebunan kelapa sawit usia 2 tahun sebesar $0,1-0,2 \%$ sedangkan pada perkebunan kelapa sawit usia 8 tahun sebesar 0,2-0,4\% dan untuk perkebunan kelapa sawit usia 16 tahun sebesar 0,2-0,3\%.

Kandungan C-organik mengalami penurunan sebesar 0,80-0,83\%. Menurut Safrizal dkk, 2016, penurunan kandungan C-organik ini diduga terjadi karena adanya aktifitas dekomposisi oleh mikroorganisme tanah, erosi bahan organik yang terjadi akibat aktifitas pada lahan gambut tersebut. Kondisi lahan gambut yang telah didrainase akan merubah kondisi gambut yang semula anaerob menjadi aerob. Hal ini mengakibatkan meningkatnya aktifitas mikroorganisme perombak bahan organik tanah.

Pada lahan gambut yang dialih fungsikan menjadi perkebunan kelapa sawit, mengalami perubahan kandungan $\mathrm{N}$-total. Penurunan kandungan $\mathrm{N}$-total pada konversi lahan gambut murni menjadi perkebunan kelapa sawit terjadi pada setiap usia kelapa 
sawit yang diujikan, baik itu umur tanam 2 tahun, 8 tahun maupun 16 tahun. Penurunan kadar N-total yang terjadi sebesar 0,4-0,5\%.

Tabel 1. Hasil Analisis Kimia Tanah

\begin{tabular}{|c|c|c|c|c|c|c|}
\hline \multirow{2}{*}{ No. } & \multirow{2}{*}{\multicolumn{2}{|c|}{ Parameter Analisis }} & \multicolumn{4}{|c|}{ Sampel } \\
\hline & & & \multirow{2}{*}{$\begin{array}{c}\text { Lahan } \\
\text { Gambut } \\
\text { Murni }\end{array}$} & \multirow{2}{*}{$\begin{array}{c}\begin{array}{c}\text { Kelapa } \\
\text { Sawit } 2 \\
\text { tahun }\end{array} \\
3,36\end{array}$} & \multirow{2}{*}{$\begin{array}{c}\begin{array}{c}\text { Kelapa } \\
\text { Sawit } 8 \\
\text { tahun }\end{array} \\
4,11\end{array}$} & \multirow{2}{*}{$\begin{array}{c}\text { Kelapa } \\
\text { Sawit } 16 \\
\text { tahun }\end{array}$} \\
\hline \multirow{2}{*}{1.} & \multirow{2}{*}{$\mathrm{Ph}$} & $\mathrm{KCl}$ & & & & \\
\hline & & $\mathrm{H}_{2} \mathrm{O}$ & 3,55 & 3,96 & 4,35 & 427 \\
\hline 2. & \multicolumn{2}{|l|}{ C-Organik (\%) } & 44,66 & 8,70 & 7,15 & 8,51 \\
\hline 3. & \multicolumn{2}{|l|}{ N-Total (\%) } & 1,77 & 0,92 & 0,79 & 0,88 \\
\hline 4. & \multicolumn{2}{|l|}{ P-tersedia (ppm) } & 153,75 & 73,88 & 70,20 & 81,69 \\
\hline 5. & \multicolumn{2}{|l|}{ KTK $(\mathrm{cmol} / \mathrm{kg})$} & 91,81 & 39,52 & 25,73 & 28,12 \\
\hline \multirow{4}{*}{6.} & \multirow{4}{*}{$\begin{array}{l}\text { Basa Kation } \\
\text { (cmol/kg) }\end{array}$} & K-dd & 0,21 & 0,10 & 0,10 & 0,08 \\
\hline & & Ca-dd & 1,87 & 1,08 & 0,71 & 0,42 \\
\hline & & Mg-dd & 0,97 & 0,40 & 0,24 & 0,16 \\
\hline & & $\mathrm{Na}-\mathrm{dd}$ & 0,35 & 0,17 & 0,15 & 0,13 \\
\hline
\end{tabular}

Turunnya nilai $\mathrm{N}$-total tanah diduga karena terjadinya degradasi bahan organik dan perubahan $\mathrm{pH}$ tanah yang tidak signifikan dan masih tergolong sangat asam. Hal ini mengakibatkan mikroorganisme perombak bahan organik tanah dan penambat $\mathrm{N}$ belum dapat bekerja secara optimal. Aktivitas mikroorganisme tanah sangat dipengaruhi oleh kondisi $\mathrm{pH}$ tanah. Pada tanah yang memiliki $\mathrm{pH}$ asam, maka aktifitas mikroorganismenya akan sangat rendah (Suwondo, 2002).

Perubahan penggunaan lahan gambut menjadi perkebunan kelapa sawit menyebabkan terjadinya penurunan kandungan P-tersedia. Penurunan yang terjadi sebesar 0,46-0,51\%. Penurunan nilai ini diduga karena pencucian hara, terangkutnya hara oleh tanaman, subsiden atau pemadatan dan rendahnya nilai $\mathrm{pH}$. Penurunan kandungan P-tersedia yang terjadi pada sawit usia 8 tahun dan 16 tahun sesuai dengan pernyataan Anwar et al (2001), yang menerangkan bahwa perubahan tingkat kesuburan tanah pada lahan yang dikonversi menjadi perkebunan kelapa sawit disebabkan oleh terangkutnya unsur hara oleh tanaman saat produksi (panen).

Lahan gambut yang dikonversi menjadi perkebunan kelapa sawit mengalami penurunan nilai kapasitas tukar kation. Penurunan kapasitas tukar kation yang terjadi pada perkebunan kelapa sawit diduga karena semakin berkurangnya ketersediaan bahan organik dan dihentikannya perlakuan pemupukan. Menurut Rusdiana dan Lubis (2012), menyebutkan bahwa nilai kapasitas tukar kation yang tinggi dipengaruhi oleh $\mathrm{pH}$ tanah dan ketersediaan bahan organik. Degradasi bahan organik dan C-organik inilah yang menyebabkan penurunan KTK tanah.

Hasil analisis (Gambar 1) menunjukkan Ca-dd lahan gambut murni pada kedalaman $20 \mathrm{~cm}$ sebesar $1,87 \mathrm{cmol} / \mathrm{kg}$. Sedangkan Ca-dd pada perkebunan kelapa sawit mengalami penurunan dibandingkan nilai Ca-dd pada lahan gambut murni. Pada kebun kelapa sawit usia 2 tahun, Ca-dd sebesar $1,08 \mathrm{cmol} / \mathrm{kg}$ yang berarti mengalami penurunan sebesar $42,24 \%$. Sedangkan pada kebun kelapa sawit usia 8 tahun, Ca-dd mengalami penurunan 
sebesar 62,03 \% dan pada kebun kelapa sawit usia 16 tahun, Ca-dd mengalami penurunan sebesar $77,54 \%$.

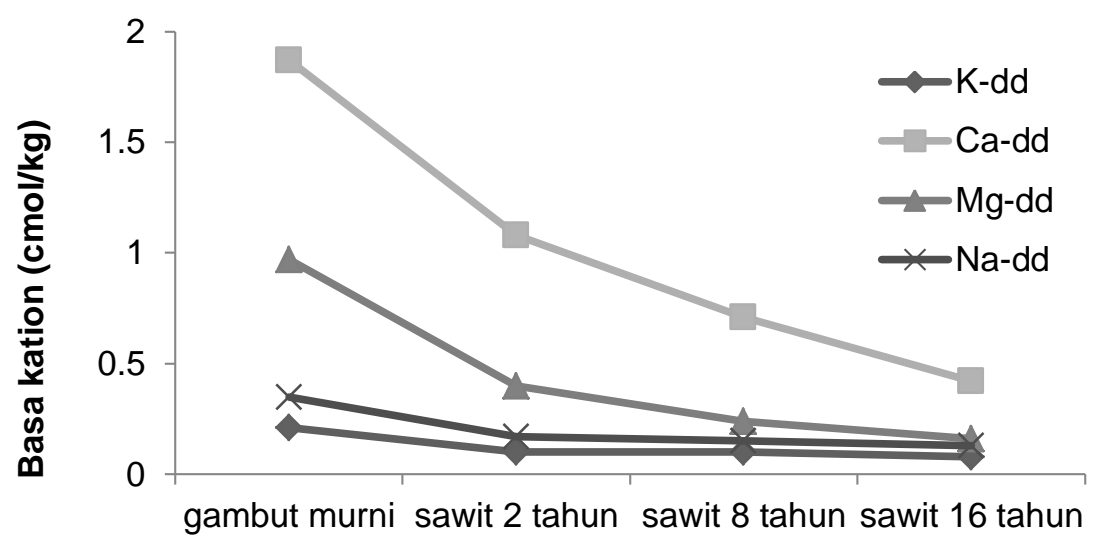

\section{Sampel}

Gambar 1. Grafik perubahan kadar kation basa

Hasil analisis Mg-dd (Gambar 1) menunjukkan bahwa lahan gambut murni yang dikonversi menjadi kebun kelapa sawit mengalami penurunan seiring pertambahan usia tanaman. Mg-dd pada lahan gambut murni di kedalaman $20 \mathrm{~cm}$ sebesar 0,97 cmol/ kg. Kandungan Mg-dd turun sebesar 58,76\% menjadi 0,40 cmol/kg pada kebun kelapa sawit 2 tahun. Pada kelapa sawit usia 8 tahun, Mg-dd turun sebesar 75,25 \% menjadi 0,24 cmol/kg. Sedangkan pada kebun kelapa sawit usia 16 tahun, Mg-dd sebesar 0,16 $\mathrm{cmol} / \mathrm{kg}$, yang berarti mengalami penurunan sebesar 83,5 \% dari Mg-dd yang terdapat pada lahan gambut murni.

Hasil analisis K-dd (Gambar 1) pada lahan gambut sekunder sebesar 0,21 $\mathrm{cmol} / \mathrm{kg}$ dan berangsur-angsur mengalami penurunan setelah dikonversi menjadi kebun kelapa sawit. Pada kebun kelapa sawit usia 2 tahun dan 8 tahun, nilai K-dd mengalami penurunan yang sama dibandingkan lahan gambut murni yaitu $0,10 \mathrm{cmol} / \mathrm{kg}$. Sedangkan pada kebun kelapa sawit usia 16 tahun, K-dd mengalami penurunan sebesar 61,9\% menjadi $0,08 \mathrm{cmol} / \mathrm{kg}$.

Hasil analisis Na-dd (Gambar 1) pada lahan gambut murni yang dikonversi menjadi perkebunan kelapa sawit juga mengalami penurunan seiring pertambahan usia tanaman. Lahan gambut murni memiliki nilai $\mathrm{Na}$-dd sebesar $0,35 \mathrm{cmol} / \mathrm{kg}$ dan pada kebun kelapa sawit usia 2 tahun turun sebesar 50\% menjadi 0,17 cmol/ $\mathrm{kg}$. Na-dd pada kebun kelapa sawit usia 8 tahun sebesar $0,15 \mathrm{cmol} / \mathrm{kg}$ atau turun $57,14 \%$ dari nilai Na-dd lahan gambut murni, dan pada kebun kelapa sawit usia 16 tahun, nilai Na-dd mengalami penurunan $62,85 \%$ menjadi $0,13 \mathrm{cmol} / \mathrm{kg}$.

Penurunan yang terjadi diduga karena upaya pengembalian hara yang terpakai oleh tanah tidak berlangsung maksimal. Hartatik et al (2004), menerangkan bahwa perlakuan pemupukan yang dilakukan dapat mengembalikan hara dalam tanah yang terangkut oleh 
tanaman. Pemanfaatan lahan gambut sebagai lahan pertanian tanpa upaya perbaikan hara tanah dapat memperburuk kondisi ketersediaan hara dalam tanah (Sembiring, 2008).

Kandungan Na yang rendah dapat pula disebabkan karena kondisi gambut yang selalu jenuh air dan hanya berasal dari akumulasi bahan organik, sehingga tidak adanya penambahan unsur mineral yang merupakan sumber utama $\mathrm{Na}$ (Nugroho et al, 2013). Selain itu kondisi gambut yang dominan banyak air juga sangat berpengaruh terhadap pencucian hara tanah, terlebih lagi sampling dilakukan ketika musim penghujan.

Kandungan $\mathrm{Mg}$ yang lebih tinggi diduga mempengaruhi rendahnya ketersediaan $\mathrm{K}$ pada lahan gambut. Hal ini sesuai dengan Arsyad et al (2012), yang menyatakan bahwa sifat antagonis $\mathrm{K}$ dan $\mathrm{Mg}$ sangat berpengaruh terhadap ketersediaannya dalam tanah. Tingginya nilai $\mathrm{Mg}$ dalam tanah maka akan mempengaruhi ketersediaan $\mathrm{K}$ dalam tanah.

\section{Dampak Alih Fungsi Lahan Gambut sebagai Perkebunan Kelapa Sawit}

Konversi lahan gambut menjadi perkebunan kelapa sawit sangat berpengaruh pada nilai kesuburan tanah itu sendiri. Berdasarkan hasil analisis kimia tanah, telah dijelaskan bahwa beberapa kandungan unsur hara tanah mengalami perubahan dan bahkan penurunan. Hal ini diduga karena adanya perlakuan pemupukan sebagai upaya pengembalian hara yang terangkut oleh tanaman saat panen tidak berlangsung dengan optimal. Dalam jangka panjang, adanya penurunan beberapa kandungan unsur hara pada tanah gambut dapat menyebabkan berkurangnya kesuburan tanah gambut itu sendiri. Dengan demikian, perlu adanya upaya-upaya perbaikan hara tanah agar kondisi tidak semakin buruk. Rini et al (2009) menerangkan bahwa upaya pemupukan yang dilakukan dapat memperbaiki kandungan hara dalam tanah yang terbawa atau terpakai oleh tanaman.

\section{KESIMPULAN}

Berdasarkan hasil penelitian, dapat disimpulkan bahwa karakteristik sifat kimia lahan gambut yang sudah dikonversi menjadi perkebunan kelapa sawit mengalami perubahan di antaranya pada nilai kenaikan $\mathrm{pH}$ baik itu $\mathrm{H}_{2} \mathrm{O}$ maupun $\mathrm{KCl}$ dan mengalami penurunan pada parameter analisis sifat kimia lain yaitu penurunan C-organik, N-total, Mg-dd, Na-dd, P-tersedia dan nilai Kapasitas Tukar Kation (KTK). Alih fungsi lahan gambut murni menjadi perkebunan kelapa sawit menunjukkan terjadinya perubahan sifat kimia tanah. Perlakuan pemupukan sebagai upaya pengembalian hara yang terangkut oleh tanaman saat panen tidak berlangsung dengan optimal. Dengan demikian, perlu adanya upaya perbaikan hara tanah agar kondisi tidak semakin buruk.

\section{UCAPAN TERIMA KASIH}

Ucapan terimakasih penulis sampaikan kepada Kementerian Riset, Teknologi dan Pendidikan Tinggi (Ristekdikti) atas dana hibah kegiatan pelaksanaan Penelitian Dosen 
Pemula dengan nomor: DIPA-042.06.1.401516/2018 yang telah diberikan dan semua pihak yang membantu dalam penelitian ini.

\section{DAFTAR PUSTAKA}

Agus, F. dan Subiksa, I. G. M. 2008. Lahan Gambut: Potensi untuk Pertanian dan Aspek Lingkugan. Balai Penelitian Tanah. Bogor. 36 hal.

Anwar S., Dja'far dan Koedadari A.D. 2001. Defisiensi Magnesium (Mg) pada Tanaman Kelapa Sawit: Study Kasus di Kebun Tj. Keliling Kabupaten Langkat Sumatera Utara. Warta PPKS. 9(3):97-102.

Arsyad, A.R., H. Junedi, dan Y. Farni. 2012. Pemupukan Kelapa Sawit Berdasarkan Potensi Produksi Untuk Meningkatkan Hasil Tandan Buah Segar (TBS) Pada Lahan Marginal Kumpeh. Jurnal Penelitian Universitas Jambi. 14(1): 29-36.

Hartatik W., I.G.M. Subiksa, dan A.I. Dairiah. 2011. Sifat Fisik dan Kimia Tanah Gambut. Balai Penelitian Tanah. Bogor. 45-56 hal.

Jumin, H. B. 1998. Agronomi. Raja Grafindo Persada. Jakarta.

Notohadiprawito T. 1996. "Perspektif Pengembangan Lahan Basah: Maslahat dan Mudarat". Dalam: Makalah pada Seminar Nasional Peringatan Setengah Abad Fakultas Pertanian Univ Gadjah Mada. Yogyakarta, 25 -26 September 1996. $14 \mathrm{hlm}$.

Nugroho Tri Cahyo, Oksana dan Ervina Aryanti. 2013. Analisis Sifat Kimia Tanah Gambut Yang Dikonversi Menjadi Perkebunan Kelapa Sawit di Kabupaten Kampar. Jurnal Agroteknologi, 4(1), 25-30.

Page, S.E. and J.O. Rieley. 1998. Tropical Peatland : a review of their natural resource functions, with particular reference to Southeast Asia, International Peat Journal, 8, 95-106.

Rieley, J. O., Page, S. E., Limin, S.H., and Winarti, S. 1997. The peatland resource of Indonsia and the Kalimantan Peat swamp forest research project. In. Proc. Biodiversity and Sustainability of Tropical Peatlands (J. O. Rieley and S.E. Page. Eds.) Samara Publ. Ltd. Cardigan.

Rini, N. Hazli, S. Hamzar, dan B.P. Teguh. 2009. Pemberian Fly Ash Pada Lahan Gambut Untuk Mereduksi Asam Humat dan Kaitannya Terhadap Kalsium (Ca) dan Magnesium (Mg). Jurnal Teroka. 9(2): 143-154.

Rusdiana O., dan R.S. Lubis. 2012. Pendugaan Korelasi Antara Karakteristik Tanah Terhadap Cadangan Karbon (Carbon Stock) Pada Hutan Sekunder. Jurnal Silvikultur Tropika. 3(1): 14-21.

Safrizal, Oksana, dan Robbana Saragih. 2016. Analisis Sifat Kimia Tanah Gambut Pada Tiga Tipe Lahan Di Desa Pangkalan Panduk Kecamatan Kerumutan Kabupaten Pelalawan. Jurnal Agroteknologi, 7(1), 27-32.

Sembiring, S. 2008. Sifat Kimia dan Fisik Tanah pada Areal Bekas Tambang Bauksit di Pulau Bintan Kepulauan Riau. Jurnal Kehutanan, 5(2), 123-134.

Silvius, M. J. and W. Giesen. 1996. Toard integrated management of Swmp forest A case study from Sumatera. In. Tropical Lowland Peatlands of Southeast Asia (E.Maltby, C. Immirizi and R.J. Safford, Eds.). IUCN. Gland. Switzerland. p.247-267

Suwondo, S. Sabihan, Sumardjo dan B.Paramudya. 2012. Efek Pembukaan Lahan Terhadap Karakteristik Biofisik Gambut Pada Perkebunan Kelapa Sawit Di Kabupaten Bengkalis. Jurnal Natural Indonesia, 14(2), 143-149. 